\title{
Comparative Study of Sacroiliac Joint Dysfunction and Lumbar Flexibility between Normal Subjects and Sacroiliac Joint Dysfunction Patients
}

\author{
AHMED M.A. SHADY, M.Sc.*; HAMED M. EL-KHOZAMY, Ph.D.**; SALWA F. ABDEL MEGID, Ph.D.** and \\ WALID ABD EL BAKY, M.D.*** \\ The Department of Musculoskeletal Disorders \& their Surgeries Physical Therapy, Public Hospital, Menofyia*, \\ The Departments of Physical Therapy for Musculoskeletal Disorders \& their Surgeries, Faculty of Physical Therapy**, \\ Cairo University and The Department of Orthopedic Surgery***, Health Insurance Hospital, Cairo, Egypt
}

\begin{abstract}
Background: Low Back Pain (LBP) is a symptom rather than a disease diagnosis. Pathology in the low back might affect the pattern of movement rather than only the range of movement ROM. Approximately $10 \%$ with LBP do not respond to treatment and develop chronic LBP. The cause for this nonresponse to treatment is lack of specific diagnosis and inability to distinguish, in some people, pain arising from the Sacroiliac Joints (SIJs) or the lumbar spine.
\end{abstract}

Aim of Study: This study was conducted to identify the relationship between Sacroiliac joint dysfunction SIJD and lumbar spine movement in sagittal and frontal plan.

Subjects and Methods: Forty participants aging 20:40 years divided into 2 groups. Group (A) consisted of 20 healthy participants, Group (B) SIJD consisted of 20 subjects were positive of at least 3 SIJ provocative test. All the participants on the study, pelvic asymmetry was measured by PALM device also spinal flexibilityof lumbar spine was assessed in sagittal and frontal plan.

Results: There was negative weak significant correlation between mean difference of pelvic inclination and ExtensionFlexion E-F of lumbar $(r=0.405, p=0.014 *)$. While, no significant correlation between mean difference of pelvic inclination and lumbar flexion, left side bending, right side bending, and over all side bending L-R of lumbar.

Conclusion: There was change of lumbar spine mobility in sagittal plan on extension and overall sagittal ROM with SIJD patients, though in comparison between groups it showed that patient with SIJD had less overall frontal plan ROM.

Key Words: Sacroiliac joint dysfunction - Mechanical low back pain - Lumbar flexibility.

\section{Introduction}

THE sacroiliac joint dysfunction SIJD in a primary LBP population demonstrated $31.7 \%$ of patients

Correspondence to: Dr. Ahmed M.A. Shady, The Department of Musculoskeletal Disorders \& their Surgeries Physical Therapy, Public Hospital, Menofyia
[1]. SIJ is a potential pain generator that must be considered within the differential diagnosis of LBP [2]. SIJ pain is a relatively common cause of LBP with a prevalence ranging from 10 to $27 \%$ [3-5] History, physical examination, and imaging often have low sensitivity and specificity for the diagnosis of SIJD. For these reasons, diagnosis and treatment often remains a challenge [6]

The most typical site of pain from the SIJ is at the junction with the sacrum, the medial portion of the buttock. However, pain radiating to the posterolateral aspect of the greater trochanter and to the posterolateral aspect of the thigh is common [7-10]. Unilateral pain is more common than bilateral by as much as a 4:1 ratio. Patterns of somatic referred SIJ pain have been identified and can vary significantly $[\mathbf{1 1 , 1 2 ]}$.

Pelvic asymmetry in the sagittal plane, namely, iliac rotation asymmetry, is often linked to SIJ dysfunction, and refers to malalignment between the left and right innominate bones [13] . It is presumed that pelvic asymmetry alters the body mechanics, puts various body segments under strain, and, therefore, contributes to musculoskeletal pain [14-17]. In particular, compensation for pelvic asymmetry that occurs in the musculoskeletal system alters the mechanics of the lumbar spine as reflected. These secondary alterations are presumed to contribute to LBP $[\mathbf{1 8 , 1 9 ]}$

The magnitude and timing of such lumbar and pelvic contributions to trunk motion have been investigated extensively for different purposes in the rehabilitation under the label of lumbopelvic rhythm LPR [20] Several authors have proposed that repeated LPR is a factor in the development 
and course of LBP [21-23]. Increased LPR, particularly early in the range of trunk and limb movements, has been associated with LBP [24-29]. This study has been conducted to compare SIJD and lumbar flexibility between normal subjects and SIJD patients between patients with SIJD on sagittal and frontal plan. And identify the significant relationship between SIJD and lumbar spine movement.

\section{Subjects and Methods}

Study selection: Inclusion and exclusion criteria:

This study was an observational case control correlation study designed to identify the significant relationship between SIJD and lumbar spine movement in sagittal and frontal plan. Participants (forty males, 20-40 years of age) were recruited locally on Faculty of Physical Therapy, Cairo University outpatient clinic July 2019. Informed consent form was signed by the participants. All potential participants on the study group were initially screened for eligibility. Subjects were excluded if they had a history of rheumatoid arthritis, lower extremity fracture, neurological sensory or motor deficits, history of surgeries on the back, spinal deformities, and subjects with true leg length discrepancy. We invited local physical therapy clinics to refer subjects diagnosed with chronic LBP (individuals with unilateral chronic LBP, more than 3 month and not exceeding 3 years) below level of L5, or pain over posterior aspect of SIJ around posterior superior iliac spine and buttock with and without above knee thigh pain. And patients who were positive with at least 3 provocation SIJ test. Subjects were included in this study and classified into two groups: Group (A) Control group with no history of LBP in the last 6 month before the study $(n=20$ males, mean age and body mass index values of $30.66 \pm 4.40$ years and $25.84 \pm 3.27 \mathrm{~kg} / \mathrm{m}^{2}$ respective- ly) and LBP Group (B) (n=20 males, patients with diagnosis of SIJD with mean age and body mass index values of $28.05 \pm 6.05$ years and $23.43 \pm 6.8$ $\mathrm{kg} / \mathrm{m}^{2}$ respectively).

Equipment: To assess pelvic asymmetry, pelvic inclinometer PALM (USA made) was used to measure the difference between right and left side iliac rotation, with participant in standing position. PALM device appears to provide a potentially reliable measure of pelvic inclination in pelvic dysfunction [30]. To measure lumbar mobility, Spinal Mouse SM (Swiss made) was used. SM was considered as practical due to its ease of access and low-cost processing time as opposed to the access to CT and MRI facilities. SM was previously investigated for its repeatability and reliability by others for clinical applications [31-35]

Procedures: First, personal information and relevant history of each participant was taken and recorded. Each patient was verbally informed regarding the purpose of the current study then, the individual was asked to sign an informed consent form. Clinical testing was done before testing procedure to insure the patient had positive results in (3) SIJ provocation tests.

\section{Testing procedures:}

1- Lumbar flexibility assessment: The measurements were made in a quiet environment. The patients are asked to stand symmetrically, dividing their weight equally between the two feet as much as possible. The C7-S3 vertebral spinal processes are determined and marked with a marker. The patient is standing up straight in the anatomical position Fig. (1). The SM is then moved downwards over the spinal criteria points.

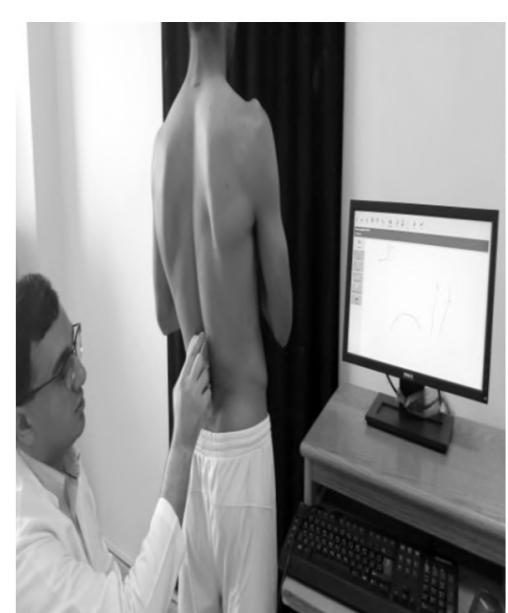

(A)

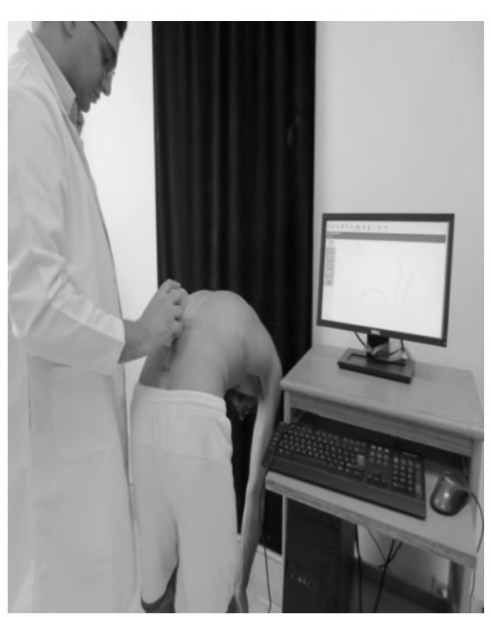

(B)

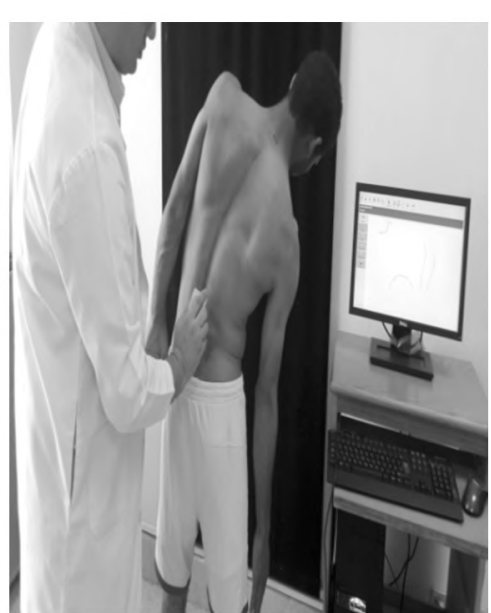

(C)

Fig. (1): (A) Extension. (B) Flexion. (C) Side bending. 
The data transferred to the computer through the SM are analyzed and the general mobility of all lumbar spines is provided. Assessment will be done for side bending,flexion, and extension.

2- Measurement procedures for pelvic inclinometer PALM: The subjects were measured while in equal symmetrical standing position but no footwear on a level floor. The raters used a PALM to take measurements for pelvic tilt on each side of the pelvis. For each measurement of pelvic tilt, standard instructions are used per the manufacturer's guidelines, as follows: With each index finger slightly prominent ready for concurrent palpation of the posterior superior iliac spine and anterior superior iliac spine, the practitioner positions the PALM on the side of the innominate bone and takes a reading. The practitioner moves their index finger over the most prominent point of the iliac crests until the apex is established for the measuring Fig. (2).

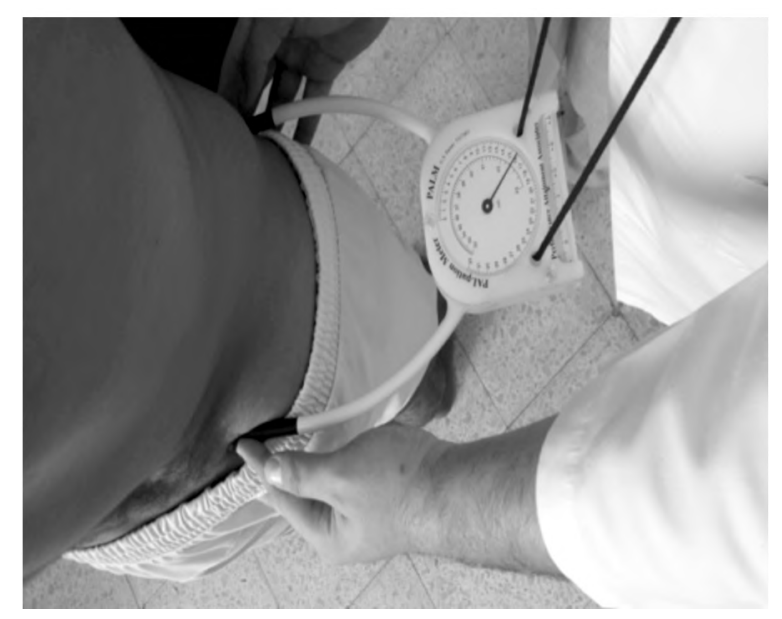

Fig. (2): Pelvic inclination measurement.

\section{Statistical analysis:}

Statistical analysis was conducted using SPSS for windows, Version 22 (SPSS, Inc., Chicago, IL). Pearson product moment correlation coefficient was used to determine the correlations among the variables. The initial alpha level for the correlation analysis was set at 0.05 . As well as, the current study involved one independent variable, it was the (tested groups); between subject factor which had two levels (Group A represent healthy subjects and Group B represent subjects with SIJD). In addition, this test involved seven tested dependent variables. Prior to final analysis, data were screened for normality assumption, homogeneity of variance, and presence of extreme scores. This exploration was done as a pre-requisite for parametric calculations of the analysis of difference. Descriptive analysis using histograms with the normal distribution curve showed that the all dependent variables were normally distributed and not violates the parametric assumption for the measured dependent variable. Additionally, testing for the homogeneity of covariance revealed that there was no significant difference with $p$-values of $>0.05$. The box and whiskers plots of the tested variable after removal of the outliers were done. Normality test of data using Shapiro-Wilk test was used, that reflect the data was normally distributed for all dependent variables, so all these findings allowed the researchers to conduct parametric analysis. So, one-way MANOVA was used to compare all dependent variables between both groups. The alpha level was set at 0.05 for this test.

\section{Results}

Correlation among mean difference of pelvic inclination and all dependent variables:

As presented at (Table 1), the correlations between mean difference of pelvic inclination and other dependent variables for each group were studied through the Pearson product moment correlation coefficient. It revealed that there was positive weak significant correlation between mean difference of pelvic inclination and lumbar extension ( $r=0.377, p=0.023 *$ ). As well as, there was negative weak significant correlation between mean difference of pelvic inclination and E-F of lumbar $\left(r=-0.405, p=0.014^{*}\right)$. While, there were no significant correlation between mean difference of pelvic inclination and lumbar flexion ( $r=0.01, p=0.955)$, mean difference of pelvic inclination and left side bending ( $r=0.042, p=0.807$ ), mean difference of pelvic inclination and right side bending $(r=-0.044$, $p=0.799)$, and mean difference of pelvic inclination and L-R of lumbar ( $r=0.013, p=0.939$ ).

\section{Comparison between both groups One-way MANOVA:}

As presented in (Table 2), the mean values of mean difference of pelvic inclination increased in the patients compared with the healthy controls. One-way MANOVA revealed a significant difference for the tested variables of interest between the two tested groups $(\mathrm{F}=2.445, p=0.033)$. Multiple pairwise comparison tests (post hoc tests) revealed that the mean values of the lumbar extension, E-F of lumbar, and L-R of lumbar declined significantly in the patient group compared with the healthy group $\left(p=0.04^{*}, 0.028^{*}\right.$, and $\left.0.003^{*}\right)$ respectively. While, there was no significant differences between both groups in the other dependent variables $(p>0.05)$ (Table 2). 
Table (1): Bivariate correlations among mean difference of pelvic inclination and all dependent variables.

\begin{tabular}{lllllll}
\hline & $\begin{array}{c}\text { Lumbar } \\
\text { flexion }\end{array}$ & $\begin{array}{c}\text { Lumbar } \\
\text { extension }\end{array}$ & $\begin{array}{c}\text { Lumbar } \\
\text { E-F }\end{array}$ & $\begin{array}{c}\text { Left side } \\
\text { bending }\end{array}$ & $\begin{array}{c}\text { Right side } \\
\text { bending }\end{array}$ & $\begin{array}{c}\text { L-R of } \\
\text { lumbar }\end{array}$ \\
\hline Mean difference of & $r=0.01$ & $r=0.337$ & $r=-0.405$ & $r=0.042$ & $r=-0.044$ & $r=0.013$ \\
pelvic inclination & $p=0.955$ & $p=0.023 *$ & $p=0.014^{*}$ & $p=0.807$ & $p=0.799$ & $p=0.939$ \\
\hline
\end{tabular}

*: Significant at alpha level 0.05 .

Table (2): Descriptive statistics and multiple pairwise comparisons for all dependent variables in both groups.

\begin{tabular}{lllll}
\hline & $\begin{array}{c}\text { Group A } \\
\text { Mean } \pm \text { SD }\end{array}$ & $\begin{array}{c}\text { Group B } \\
\text { Mean } \pm \text { SD }\end{array}$ & $\begin{array}{c}\text { Mean } \\
\text { difference }\end{array}$ & $\begin{array}{c}p \text { - } \\
\text { value }\end{array}$ \\
\hline Lumbar flexion & $32.77 \pm 9.63$ & $32.83 \pm 9.43$ & -0.05 & 0.986 \\
Lumbar extension & $-46.16 \pm 7.33$ & $-40 \pm 10.14$ & -6.16 & $0.04^{*}$ \\
E-F of lumbar & $79.05 \pm 8.69$ & $72.88 \pm 7.33$ & 6.16 & $0.028^{*}$ \\
Left side bending & $18.88 \pm 6.22$ & $17.94 \pm 6.14$ & 0.94 & 0.65 \\
Right side bending & $15.83 \pm 5.32$ & $12.5 \pm 6.06$ & 3.33 & 0.089 \\
L-R of lumbar & $34.44 \pm 9.04$ & $30.61 \pm 8.65$ & 10 & $0.003^{*}$ \\
Mean difference of pelvic inclination & $0.83 \pm 2.06$ & $2.5 \pm 0.85$ & -1.66 & $0.003^{*}$ \\
\hline
\end{tabular}

*: Significant level is set at alpha level $<0.05$.

\section{Discussion}

The results of the current study concerning relationship of lumbar spine ROM and SIJD on sagittal plan disagree with those reported by Shojaei et al., [36] who concluded that Lumbar range of flexion was smaller in patients and Shojaei et al., [36]ustified that as the smaller lumbar contribution in patients with LBP compared to controls did not affect the task performance; both groups displayed a similar amount of thoracic rotation. The similar amount of thoracic movement was the result of using more pelvic rotation by patient with LBP compared to the controls. Large pelvic rotations impose higher shearing demands on the lower back [37] and are also associated with projection of a larger shearing component of internal muscle forces on the spine [38]. Therefore, an increased level of contact force on facet joints of the lumbar spine could be the negative cost of the adopted posture displayed by patients with acute LBP.

The current study measured the effect between SIJD on lumbar flexibility on sagittal plan which is different to Shojaei et al., [37] who measured effect of LBP on lumbar spine ROM and found increase of pelvic range of rotation was larger in patients, as patient with LBP compensate the smaller lumbar contribution ROM through larger pelvic rotation. In the current study it showed patients with SIJD had more load on lumbar spine motion. Also, there was significant increase in the mean difference of pelvic inclination in the patient group compared with the healthy group and which influenced Lumbar spine ROM; mean values of the lumbar extension ROM, and lumbar sagittal plan ROM of lumbar declined significantly in the patient group compared with the healthy.

Furthermore, six studies examined the relative lumbar and hip contribution to flexion movements, five [29,39-42] during forward flexion, and one [28] returning from a fully flexed position. Four of five studies investigating forward flexion found no significant difference between those with and without LBP when comparing lumbar with hip contribution (ratio) to flexion ROM at end range. A non significant but consistent effect favored reduced lumbar (compared with hip) contribution to flexion for those with LBP. Three studies $[28,29,41]$ found significant differences in the 'through-range' contribution of lumbar movement. Esola et al., and Porter et al., [29,41] both found significant reductions of lumbar contribution to midrange flexion but not at end range. McClure et al., 1997 [28] found a greater contribution of the lumbar spine during mid-range return from the fully flexed position (relative extension).

Neuromuscular control and load sharing have been recognized to play a role in LBP development [43-48]. O' Sullivan, [49] concluded that poor movement dysfunction of the back, the person is unknowingly damaging him or herself through faulty movement patterns. O'Sullivan [49] describes these back-pain patients not as pain avoiders, but, as pain provocateur. Relative flexibility theory HarrisHayes et al., [50] suggests that movement occurs through the pathway of least effort, e.g. if the hip movement is relatively stiff compared to that of 
the low back, then the movement is more likely to happen in the back, leading to a back-pain problem related to the direction of that particular movement. The directions or symptoms of the movement control are called flexion, extension and side flexion/rotation. Which agreed with our results as it showed with increase of pelvis asymmetry accompanied with more lumbar extension, on the other hand that increase of lumbar spine extension ROM is less compared with controlled group.

The current study results concerning relationship of lumbar spine ROM and SIJD on frontal plan disagree with those reported by Gombatto et al., [51] found that lumbar region contributions to the trunk lateral bending movement were greater in the early phases of trunk lateral bending to the left than to the right for people in the rotation with Extension subgroup. However, people in the rotation subgroup displayed no significant differences, right versus left, in the percent contribution of lumbar region motion to total trunk lateral bending motion. Gombatto et al., [51] justifies that the previous results due to the asymmetry of lumbar region contributions occurs early in the range of trunk lateral bending in the rotation with extension subgroup and because functional activities are commonly performed in the early and middle ranges of joint motion, rather than at the end ranges. Theoretically, $[\mathbf{2 3 , 5 2 , 5 3 ]}$ if the lumbar region contributes more than other regions early during trunk lateral bending movement, then the lumbar region potentially moves repeatedly during all functional activities that involve any degree of trunk lateral bending. The repetition of such lumbar region movement across the day suggests that the amount of time without loading may be insufficient for normal tissue adaptation,resulting in the accumulation of excessive tissue stress, micro trauma, and LBP symptoms. Thus, the asymmetry of the lumbar region movement pattern early during trunk lateral bending is considered to be an important contributor to the LBP problem in the rotation with extension subgroup and an important finding for identifying people in the rotation with extension subgroup [54]

On current study we measured the end range in frontal plan between right and left side bending and there were no significant correlation between mean difference of pelvic inclination and left side bending and right side bending but Gombatto et al., [51] found that the right versus left difference in the contribution of lumbar spine to trunk lateral bending was particularly evident during the early part of the trunk lateral bending motion. During the first $25 \%$ of the trunk lateral bending motion.
With agreement to our study Eisa et al., [55] study which found that the LBP group exhibited significantly higher asymmetry in the principal motion. The groups differed significantly in the pattern of coupled rotation during lateral flexion. Asymmetry in lumbar lateral flexion was highly related to two types of pelvic asymmetry: Lateral pelvic tilt LPT and iliac rotation asymmetry IRA. Asymmetry in lumbar axial rotation was highly related to IRA but weakly related to LPT. The LBP group exhibited significantly higher range and asymmetry in lumbar coupled axial rotation, but not in lumbar coupled lateral flexion.

\section{Conclusion:}

According to the results, it can be concluded that there is significant weak positive relationship between lumbar spine mobility on extension and SIJD. Moreover, negative significant weak relationship between lumbar spine overall sagittal range of motion with sacroiliac dysfunction patients, in contrast on frontal plan no relationship was found with SIJD. On the other hand, in comparison between groups it showed that patient with SIJD had less overall frontal plan ROM, sagittal and extension ROM.

\section{References}

1- O'SHEA F.D., BOYLE E., SALONEN D.C., AMMENDOLIA C., PETERSON C., HSU W. and INMAN R.D.: Inflammatory and degenerative sacroiliac joint disease in a primary back pain cohort. Arthritis Care Res. (Hoboken), 62 (4): 447-54, 2010.

2- STACY L. FORST, MICHAEL T. WHEELER, JOSEPH D. FORTIN and JOEL A. VILENSKY: The Sacroiliac Joint: Anatomy, Physiology and Clinical Significance. Pain Physician, 9: 61-8, 2006.

3- PANG W.W., MOK M.S., LIN M.L., CHANG D.P. and HWANG M.H.: Application of spinal pain mapping in the diagnosis of low back pain analysis of 104 cases. Acta. Anaesthesiol. Sin., 36 (2): 71-4, 1998.

4- MAIGNE J.Y., AIVALIKLIS A. and PFEFER F.: Results of sacroiliac joint double block and value of sacroiliac pain provocation tests in 54 patients with low back pain. Spine, 21 (16): 1889-92, 1996.

5- IRWIN R.W., WATSON T., MINICK R.P. and AMBROSIUS W.T.: Age, body mass index, and gender differences in sacroiliac joint pathology. Am. J. Phys. Med. Rehabil., 86 (1): 37-44, 2007.

6- BEHDAD HAMIDI RAVARI, SHARWINTAFAZOLI HAMILTON CHEN and DANIELLE PERRET: Diagnosis and Current Treatments for Sacroiliac Joint Dysfunction: A Review. Curr. Phys. Med. Rehabil. Rep., 2: 48-54, 2014.

7- BERTHELOR J.M., LABAT J.J., Le GOFF B., et al.: Provocative sacroiliac joint maneuvers and sacroiliac joint block are unreliable for diagnosing sacroiliac pain. Joint Bone Spine. August, 17, 2004. 
8- FORTIN J.D., APRILL C.N., PONTHIEX B. and PIER J.: Sacroiliac joint: Pain referral maps upon applying a new injection/arthrography technique, part II: Clinical evaluation. Spine, 13: 1482-9, 1994.

9- FORTIN J.D., APRILL C.N., PONTHIEX B. and PIER J.: Sacroiliac joint: Pain referral maps upon applying a new injection/arthrography technique, part II: Clinical evaluation. Spine, 13: 1482-9, 1994.

10- FORTIN J.D., WASHINGTON W.J. and FALCO F.J.E.: Three pathways between the sacroiliac joint and neural structures. Am. J. Neuroradiol., 20: 1429-34, 1999.

11- PRATHER H. and HUNT D.: Conservative management of low back pain, part I. Sacroiliac joint pain. Dis. Mon., 50: 670-83, 2004.

12- BERNARD T.N. T.N.Jr.: The sacroiliac joint syndrome: Pathophysiology, diagnosis, and management, in Frymoyer JW, ed. The Adult Spine Principles and Practice. New York, Raven, pp. 2107-30, 1991.

13- EGAN D.A., COLE J. and TWOMEY L.: The standing forward flexion test: An inaccurate determinant of sacroiliac joint dysfunction. Physiotherapy, 82: 236-42, 1996.

14- EGAN D.A. and AL-EISA E.: Pelvic skeletal asymmetry, postural control, and the association with low back pain: A review of the evidence. Crit. Rev. Phys. Rehabil. Med., 11: 299-338, 1999.

15- FANN A.V.: The prevalence of postural asymmetry in people with and without chronic low back pain. Arch. Phys. Med. Rehabil., 83: 1736-8, 2002.

16- AL-EISA E., EGAN D.A. and FENETY A.: The association between lateral pelvic tilt and asymmetry in sitting pressure distribution. J. Manual. Manipulative Ther., 12: 133-42, 2004.

17- RIEGGER-KRUGH C. and KEYSOR J.J.: Skeletal malalignments of the lower quarter: Correlated and compensatory motions and postures. J. Orthop. Sports Phys. Ther., 23: 164-70, 1996.

18- McCAW S.T. and BATES B.T.: Biomechanical implications of mild leg length inequality. Br. J. Sports Med., 25: 10-3, 1991.

19- EINAS AL-EISA, DAVID EGAN, KEVIN DELUZIO and RICHARD WASSERSUG: Effects of Pelvic Skeletal Asymmetry on Trunk Movement: Three-Dimensional Analysis in Healthy Individuals Versus Patients With Mechanical Low Back Pain. Spine, 31: E71-E79, 2006.

20- MILAD VAZIRIAN, LINDA R. VAN DILLEN and BABAK BAZRGARI: Lumbopelvic International Lumbopelvic rhythm in the sagittal plane: A review of the effects of participants and task characteristics, Musculoskeletal Medicine, 38: 2, 51-8, 2016.

21- ADAMS M., MAY S. and FREEMAN B.: Effect of backward bending on lumbar intervertebral discs Spine, 25 (4): 431-7, 2000.

22- McGILL S.M.: The biomechanics of low back injury: Implications on current practice in industry and the clinic. Journal of Biomechanics, 30 (5): 465-75, 1997.

23- SAHRMANN S.A.: Diagnosis and Treatment of Movement Impairment Syndromes. Mosby, Maryland Heights, MO, 2002.
24- ROUSSEL N., NIJS J., TRUIJEN S., MOTTRAM S., VAN MOORSEL A. and STASSIJNS G.: Altered lumbopelvic movement control but not generalized joint hypermobility is associated with increased injury in dancers: A prospective study. Manual Therapy, 14 (6): 630-5, 2009.

25- LUOMAJOKI H., KOOL J., De BRUIN E.D. and AIRAKSINEN O.: Movement control tests of the low back; evaluation of the difference between patients with low back pain and healthy controls. BMC Musculoskeletal Disorders, 9: 170-81, 2008.

26- SHUM G.L.K., CROSBIE J. and LEE R.Y.W.: Symptomatic and asymptomatic movement coordination of the lumbar spine and hip during an everyday activity. Spine, 30 (23): E697-E702, 2005.

27- BURNETT A.F., CORNELIUS M.W., DANKAERTS W. and O'SULLIVAN P.B.: Spinal kinematics and trunk muscle activity in cyclists: A comparison between healthy controls and non-specific chronic low back pain subjects a pilot investigation. Manual Therapy, 9 (4): 211-9, 2004.

28- McCLURE P., ESOLA M., SCHREIER R. and SIEGLER S.: Kinematic analysis of lumbar and hip motion while rising from a forward, flexed position in patients with and without a history of low back pain. Spine, 22 (5): 552-8, 1997.

29- ESOLA M.A., McCLURE P.W., FITZGERALD G.K. and SIEGLER S.: Analysis of lumbar spine and hip motion during forward bending in subjects with and without a history of low back pain. Spine, 21 (1): 71-8, 1996.

30- DACRUZ STEPHANIE NAVAL, NAFEEZ SYED and SURULIRAJ KARTHIKBABU: Intra-rater and interrater reliability of measuring pelvic tilt using the palpation meter (PALMTM) device in stroke. Int. J. Med. Health Sci. Oct., 5; 4, 2016.

31- TOPALIDOU A., TZAGARAKI G., SOUVATZI X., KONTAKI G. and KATONI P.: Evaluation of the reliability of a new non-invasive method for assessing the functionality and mobility of the spine. Acta of Bioengineering and Biomechanics, Vol. 16, pp. 117-24, 2014.

32- RIPANI M., Di CESARE A., GIOMBINI A., AGNELLO L., FAGNANI F. and PIGOZZI F.: Spinal curvature comparison of frontal measurements with the Spinal Mouse and radiographic assessment', The Journal of Sports Medicine and Physical Fitness, Vol. 48, pp. 48894, 2008.

33- GUERMAZI M., GBROUBI S., KASSIS M., JAZIRI, KESKES H., KESSOMTINI W., et al.: Validite et reproductibilite du Spinal Mouse pour I' etude de la mobiliteen flexion du rachis lombaire. Validity and reliability of Spinal Mouse to assess lumbar flexion. Ann. Readapt. Med. Phys., 49: 1727, 2006.

34- MANNION ANNE P., KNEEHT K., BALABAN G., DVORAK J. and GRUB D.: A new skin surface device for measuring the curvature and global and segmental ranges of motion of the spine: Reliability of measurements and comparison with data reviewed from the Literature. Eur. Spine, 13: 122-36, 2004.

35- POST R.B., LEFERINK V.L.M.: Spinal mobility: Sagittal range of motion measured with Spinal Mouse, a new noninvasive device. Arch. Orthop. Trauma Surg., 124: 18792, 2004. 
36- IMAN SHOJAEI, MILAD VAZIRIAN, ELIZABETH G. SALT, LINDA R. VAN DILLEN and BABAK BAZRGARI: Timing and magnitude of lumbar spine contribution to trunk forward bending and backward return in patients with acute low back pain Journal of Biomechanics, 12.039, 2017.

37- SHOJAEI I., VAZIRIAN M., CROFT E., NUSSBAUM M.A. and BAZRGARI B.: Age related differences in mechanical demands imposed on the lower back by manual material handling tasks. J. Biomech., 49 (6): 896-903, 2015 b.

38- ARJMAND N., GAGNON D., PLAMONDON A., SHIRAZI-ADL A. and LARIVIERE C.: Comparison of trunk muscle forces and spinal loads estimated by two biomechanical models. Clin. Biomech., 24: 533-41, 2009.

39- KIM M.H., YI C.H., KWON O.Y., CHO S.H., CYNN H.S., KIM Y.H., HWANG S.H., CHOI B.R., HONG J.A. and JUNG D.H.: Comparison of lumbopelvic rhythm and flexion relaxation response between 2 different low back pain subtypes. Spine, 38 (15): 1260-7, 2013.

40- WONG T.K., LEE R.Y., WONG T.K.T. and LEE R.Y.W.: Effects of low back pain on the relationship between the movements of the lumbar spine and hip. Hum. Mov. Sci. 23 (1): 21-34, 2004.

41- PORTER J.L. and WILKINSON A.: Lumbar-hip flexion motion. A comparative study between asymptomatic and chronic low back pain in 18-to 36-year-old men. Spine, 22 (13): 1508-13. discussion 1513-04, 1997.

42- PAQUET N., MALOUIN F. and RICHARDS C.: Hipspine movement interaction and muscle activation patterns during sagittal trunk movements in low back pain patients. Spine, 15 (5): 596-603, 1994.

43- ABOUHOSSEIN A.,WEISSE B. and FERGUSON S.J.: Amultibody modelling approach to determine load sharing between passive elements of the lumbar spine Comput. Methods Biomech. Biomed. Eng., 14: 527-37, 2011.

44- HASHEMIRAD F., TALEBIAN S., OLYAEI G.R. and HATEF B.: Compensatory behavior of the postural control system to flexion-relaxation phenomena. J. Body W. Mov. Ther., 14: 418-23, 2010.

45- DUBOIS J.D., PICHÉ M., CANTIN V. and DESCARREAUX M.: Effect of experimental low back pain on neuromuscular control of the trunk in healthy volunteers and patients with chronic low back pain. J. Electromyogr. Kinesiol., 21: 774-81, 2011.

46- LEINONEN V.: Neuromuscular Control in Lumbar Disorders. Kuopion Yliopisto, 2003.

47- PANJABI M.M.: Clinical spinal instability and low back pain. J. Electromyogr. Kinesiol., 13, 371-37, 2003

48- VAN DIEËN J.H. and NUSSBAUM M.A.: Year Occupational biomechanics of the low back. In: Proceedings of the Human Factors and Ergonomics Society. Annual Meeting, 2000.

49- O'SULLIVAN P.: Diagnosis and classification of chronic low back pain disorders: Maladaptive movement and motor control impairments as underlying mechanism. Man. Ther., 10: 242e55, 2005.

50- HARRIS-HAYES M. and VAN DILLEN L.R.: The intertester reliability of physical therapists classifying low back pain problems based on the Movement System Impairment classification system. PM \& R1, (2): 117-26, 2009.

51- SARA P. GOMBATTO, DAVID R. COLLINS, SHIRLEY A. SAHRMANN, JACK R. ENGSBERG and LINDA R. VAN DILLEN: Patterns of Lumbar Region Movement During Trunk Lateral Bending in 2 Subgroups of People With Low Back Pain Phys. Ther., Volume 87 Number 4 2007.

52- PANJABI M.M.: A hypothesis of chronic back pain Ligament subfailure injuries lead to muscle control dysfunction. Eur. Spine J., 15: 668-76, 2006.

53- PANJABI M.M.: The stabilizing system of the spine, part II: neutral zone and instability hypothesis. J. Spinal Disord., 5: 390-6, 1992.

54- MUELLER M.J. and MALUF K.S.: Tissue adaptation to physical stress: A proposed "physical stress theory" to guide physical therapist practice, education, and research. Phys. Ther., 82: 383-403, 2002.

55- EINAS AL-EISA, DAVID EGAN, KEVIN DELUZIO and RICHARD WASSERSUG: Effects of Pelvic Asymmetry and Low Back Pain on Trunk Kinematics During Sitting: A Comparison With Standing. Spine, 31: E135E143, 2006 


\title{
دراسة مقارنة خلل المفصل العجزى الحرقفى ومرونة المنطقة القطنية

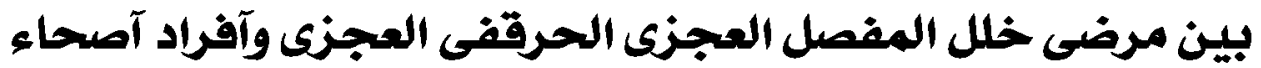

\author{
الغرض : إستقصاء العلاقة بين خلل المفصل العجزى الصرقفى وحركة المنطقة القطنية في المستقى الجانبى الآمامى. \\ الطريقة : تم تعيين • ع شخص على مجموعتين:

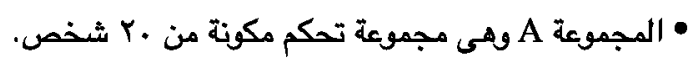

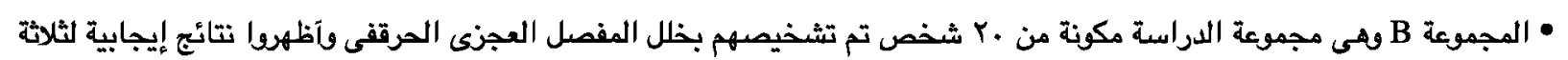

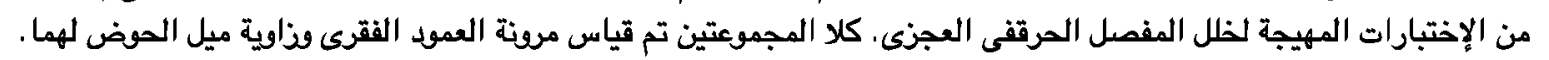

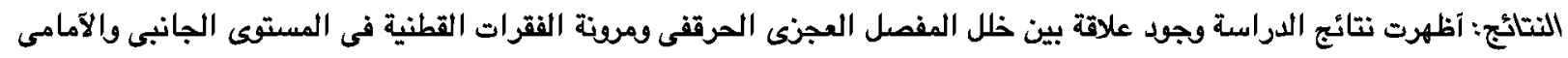

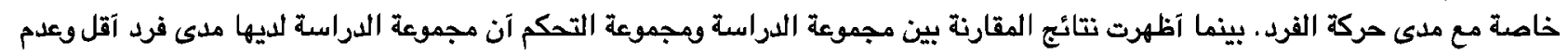
تماثل آكثر في الحوض مـ إن النتائج تبرهن على علم وجود علاقة بين خلل المفصل العجزى الحرقفى ومرونة المنطقة القطنية في المستوى الآمامى. 